\title{
Wpływ długotrwałej obróbki cieplnej na trwałość zmęczeniową bimetalu cyrkon-stal
}

\author{
The effect of long-term thermal treatment on fatigue life \\ of bimetal zirconium-steel
}

\section{Streszczenie}

W pracy opisano strukturę, właściwości mechaniczne oraz rozwój pęknięć zmęczeniowych w układach platerów cyrkon-stal zgrzewanych wybuchowo, poddanych długotrwałemu oddziaływaniu temperatury. Próbki w stanie po spojeniu wygrzewano $\mathrm{w}$ temperaturze $600{ }^{\circ} \mathrm{C}$ w czasie 10 i 100 godzin, a następnie poddano obserwacjom mikroskopowym, określono twardość, wytrzymałość na rozciąganie oraz poddano wahadłowemu zginaniu. W odkształconych próbkach zaobserwowano wzrost pęknięć zmęczeniowych równolegle do przyłożonego obciążenia, przy czym inicjacja pęknięć występowała w stali.

Słowa kluczowe: zgrzewanie wybuchowe; zginanie; zmęczenie; twardość

\begin{abstract}
The paper describes the structure, mechanical properties and fatigue cracks growth in explosively welded zirconium - carbon steel cladding system subjected to long-lasting temperature impact. After annealing at $600{ }^{\circ} \mathrm{C}$ for 10 and 100 hours the samples were subjected to microscopic observations and finally the microhardness, tensile strength and cyclic bending were determined. In the deformed specimens the initiation of fatigue cracks occurred in the steel whereas further cracks growth occurred parallel to the applied load.
\end{abstract}

Keywords: explosive welding; bending; fatigue; hardness

\section{Wstęp}

Budowa nowoczesnej, wysokoodpornej korozyjnie aparatury chemicznej i procesowej, o planowanym długim okresie eksploatacji i relatywnie niskim koszcie wytwarzania, wymaga stosowania metali reaktywnych takich jak: tytan, cyrkon, tantal oraz ich stopy. Materiały te w postaci wyrobów walcowanych, tj. blachy czy taśmy są relatywnie drogie, jednak rozwiązaniem obniżającym koszty ich wykorzystania może być zastosowanie układów warstwowych. W tego typu układach materiałem spełniającym wymogi konstrukcyjne jest blacha podstawowa (najczęściej stal odpowiedniego gatunku), na którą nakłada się cienką warstwę materiału o specjalnych właściwościach. Dotychczas jedyną technologią pozwalającą na łączenie materiałów o bardzo zróżnicowanych własnościach fizyko-chemicznych jest technologia zgrzewania wybuchowego. Technologiczne aspekty zgrzewania wybuchowego przedstawiono w licznych pracach $[1,7,8]$. Cechą charakterystyczną tej technologii jest łączenie materiałów w wyniku zderzenia z dużą prędkością blachy podstawowej z nakładaną. W efekcie w strefie połączenia występuje silne odkształcenie plastyczne oraz umocnienie łączonych materiałów. Następujące pod wpływem tych czynników zmiany strukturalne, w szeroko pojętej strefie złącza, zostały szczegółowo opisane w literaturze $[1 \div 5]$. Umocnienie oraz wzrost naprężeń w strefie połączenia są niekorzystne z punktu widzenia dalszej przeróbki materiałów platerowanych tj. prostowania, tłoczenia, obróbki skrawaniem, spawania itp. W tym przypadku istotnym zagadnieniem w produkcji materiałów platerowanych jest obróbka cieplna. Celowość, a nawet konieczność przeprowadzenia tego typu obróbki udokumentowano w pracach [6,7]. Długotrwałe oddziaływanie wysokiej temperatury $w$ warunkach eksploatacyjnych nie pozostaje obojętne na własności mechaniczne, jak również zmiany strukturalne w strefie połączenia powodujące najczęściej spadek własności wytrzymałościowych.

W pracy analizowano wpływ długotrwałego oddziaływania wysokiej temperatury na zmiany strukturalne oraz właściwości mechaniczne w bimetalach cyrkon-stal węglowa zgrzewanych wybuchowo, które poddano obróbce cieplnej w temperaturze $600{ }^{\circ} \mathrm{C}$ przez 10 (pr. $10 \mathrm{~h}$ ) i 100 godzin (pr. 100 h) w atmosferze obojętnej. W oparciu o wykonane badania makro- i mikrostrukturalne, jak również powiązane z nimi badania mechaniczne przedstawiono wpływ temperatury i czasu na właściwości złącza cyrkon-stal.

Dr Mariusz Prażmowski; dr hab. inż. Dariusz Rozumek, prof. PO - Politechnika Opolska; prof. dr hab. inż. Henryk Paul - Instytut Metalurgii i Inżynierii Materiałowej PAN w Krakowie.

Autor korespondencyjny/Corresponding author. m.prazmowski@po.opole.pl 
Tablica I. Skład chemiczny i właściwości mechaniczne stali P 355NL2 oraz stopu cyrkonu Zr 700

Table I. Chemical composition and mechanical properties of P 355NL2 steel and Zr 700 alloy

\begin{tabular}{|c|c|c|c|c|c|c|c|c|c|c|c|c|c|c|}
\hline \multirow{2}{*}{ Materiał } & \multicolumn{14}{|c|}{ Udział pierwiastków [\% at.] } \\
\hline & C & $\mathrm{Mn}$ & $\mathrm{Si}$ & $\mathrm{P}$ & S & $\mathrm{Ni}$ & $\mathrm{Cr}$ & $\mathrm{H}$ & $\mathrm{N}$ & $\mathrm{Al}$ & Mo & 0 & $\mathrm{Nb}$ & $\mathrm{Fe}$ \\
\hline $\mathrm{Zr} 700$ & $<0,002$ & - & - & - & - & - & 0,05 & $<0,0003$ & $<0,002$ & - & - & 0,05 & - & 0,05 \\
\hline \multirow[t]{3}{*}{ P355L2N } & 0,170 & 1,130 & 0,345 & 0,008 & 0,001 & 0,285 & 0,150 & - & 0,004 & 0,045 & 0,035 & - & 0,019 & reszta \\
\hline & \multicolumn{14}{|c|}{ Własności mechaniczne } \\
\hline & \multicolumn{4}{|c|}{$\mathrm{R}_{\mathrm{e}}[\mathrm{MPa}]$} & \multicolumn{4}{|c|}{$\mathrm{R}_{\mathrm{m}}[\mathrm{MPa}]$} & \multicolumn{3}{|c|}{$\mathrm{E}[\mathrm{GPa}]$} & \multicolumn{3}{|c|}{$\mathrm{A}_{5}[\%]$} \\
\hline $\mathrm{Zr} 700$ & \multicolumn{4}{|c|}{143} & \multicolumn{4}{|c|}{300} & \multicolumn{3}{|c|}{100} & \multicolumn{3}{|c|}{31} \\
\hline P355L2N & \multicolumn{4}{|c|}{402} & \multicolumn{4}{|c|}{511} & \multicolumn{3}{|c|}{210} & \multicolumn{3}{|c|}{27} \\
\hline
\end{tabular}

\section{Materiał do badań i metodyka badań}

Materiałem do badań była płyta bimetalowa o wymiarach 300 x 500 mm wykonana technologią zgrzewania wybuchowego. Materiałem podstawowym w tym układzie jest blacha ze stali niestopowej (w gatunku P355NL2) o grubości $22 \mathrm{~mm}$, natomiast materiałem nakładanym blacha z czystego technicznie cyrkonu (Zr700) o grubości 3,15 mm. W tablicy I przedstawiono skład chemiczny oraz właściwości mechaniczne łączonych materiałów.

Szczegółowy opis wykonania układu bimetalowego cyrkon-stal w procesie spajania wybuchowego przedstawiono w pracach $[1,5,8]$. Z bimetalu pobrano materiał do badań mikroskopowych, mechanicznych i zmęczeniowych. Próbki do badań zmęczeniowych wycięto z bimetalu równolegle do kierunku propagacji frontu detonacji, a następnie przygotowano zgodnie z normą ASTM D 3165-95. Jej kształt i wymiary przedstawiono w pracy [5]. Przygotowane próbki zatopiono w osłonie ze szkła kwarcowego w warunkach wysokiej próżni (rys. 1a i 1b), które następnie poddano obróbce cieplnej w elektrycznym piecu muflowy LMH 04/12 firmy LAC.

Próbki w stanie po spojeniu oraz wygrzewane poddano obserwacjom mikroskopowym. Sposób preparatyki zgładów metalograficznych do badań przedstawiono $\mathrm{w}$ pracy [9]. Końcowym etapem przygotowania zgładów było trawienie chemiczne ( $3 \%$ roztworem $\mathrm{HNO}_{3} \mathrm{w} \mathrm{C}_{2} \mathrm{H}_{5} \mathrm{OH}$ ) w celu ujawnienia struktury stali oraz granicy występowania obszarów przetopionych. Badania metalograficzne prowadzono na mikroskopie optycznym OLYMPUS IX 70 z kamerą cyfrową oraz oprogramowaniem do analizy obrazu OPTA-TECH. Dla bimetalu po spojeniu oraz po obróbce cieplnej analizowano zmiany umocnienia $\mathrm{w}$ strefie połączenia $\mathrm{w}$ oparciu o pomiary twardości metodą Vickersa, wykonane przy obciążeniu 50G i 100G. Metodykę prowadzenia pomiarów przedstawiono w pracy $[5,6]$. Wykonano także pomiary wytrzymałości na rozciąganie $R_{m}$ (po spojeniu oraz po OC) w oparciu o badanie nienormatywnych próbek na maszynie wytrzymałościowej Instron 3382. Kształt, wymiary oraz schemat wykonania próby przedstawiono w pracy [2].
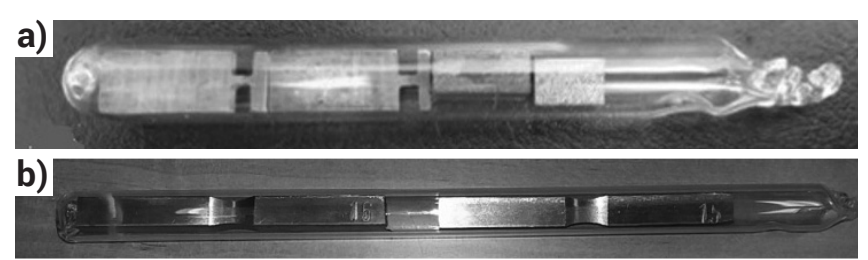

Rys. 1. Obróbka cieplna bimetali - próbka zatopiona w ampule kwarcowej do badań: a) metalograficznych i wytrzymałości, b) zmęczeniowych

Fig. 1. Heat treatment of bimetal - a specimen enclosed in glass ampule for. a) metallographic observations and strength, b) fatigue tests

\section{Wyniki badań i ich analiza}

\section{Analizy mikroskopowe}

W przypadku plateru w stanie po spojeniu (pr. W) oraz do obróbki cieplnej pobrano próbki o wymiarze $6 \times 6 \times 10 \mathrm{~mm}$, który obejmował całkowity przekrój blachy nakładanej oraz taki sam przekrój blachy podstawowej. Szczegółową charakterystykę granicy połączenia przeprowadzono na mikroskopie metalograficznym OLYMPUS IX 70 wyposażonym w oprogramowanie do analizy obrazu, mierząc podstawowe parametry, tj. długość (n) i wysokość (h) fali oraz pole powierzchni obszarów przetopionych $\left(\mathrm{P}_{\mathrm{i}}\right)$. Schemat wykonywania pomiarów oraz wyniki przedstawiono w pracach $[2,5,9]$. Strukturę blachy cyrkonowej oraz stalowej w stanie wyjściowym, tj. przed procesem spajania oraz charakterystykę granicy połączenia przedstawiono w pracach $[2,5]$. W przypadku próbek poddanych obróbce cieplnej nie prowadzono analiz związanych z charakterystyką strefy połączenia, gdyż w przypadku materiałów platerowanych obróbka cieplna nie powoduje zmian parametrów fali. Istotne z punktu widzenia analiz mikroskopowych są zmiany strukturalne występujące pod wpływem oddziaływania temperatury w czasie. Po 10 godzinach obróbki w stali zaobserwowano zrekrystalizowane ziarna ferrytu, o czym świadczy ich równoosiowy kształt oraz odkształcone, nieliczne ziarna perlitu (rys. 2a). W warstwie bezpośrednio sąsiadującej z granicą połączenia obserwowano wąską strefę o strukturze ferrytycznej, co może świadczyć o odwęgleniu tego obszaru w wyniku długotrwałego oddziaływania wysokiej temperatury. Zjawisko to nasila się wraz z wydłużeniem czasu wygrzewania do 100 godzin, po którym szerokość strefy odwęglonej w stali wynosi $215 \div 316 \mu \mathrm{m}$ (rys. $2 b$ ).

\section{Umocnienie w strefie połączenia}

W procesie łączenia z wykorzystaniem energii wybuchu materiały zderzają się $\mathrm{w}$ punkcie kolizji z prędkością kilkuset metrów na sekundę, przy ciśnieniu rzędu kilku GPa. Zjawiska te sprzyjają umocnieniu obydwu materiałów w tej strefie, co wykazano w wielu pracach [2:5]. Przeprowadzone pomiary twardości pozwoliły na określenie zmian umocnienia zarówno w strefie bezpośrednio przy granicy połączenia (do 0,5 mm), jak i w odległości do $3 \mathrm{~mm}$ od tej granicy. Otrzymane wyniki zestawiono z pomiarami twardości blach przed procesem zgrzewania wybuchowego i przedstawiono na rysunku 3.

Na podstawie rysunku 3a (wykres umocnienia w materiale nakładanym i podstawowym w zakresie odległości do $3 \mathrm{~mm}$ od granicy połączeń) można stwierdzić, że największe umocnienie występuje w obu łączonych materiałach w odległości 0,02 mm od tej granicy. Wraz ze wzrostem 

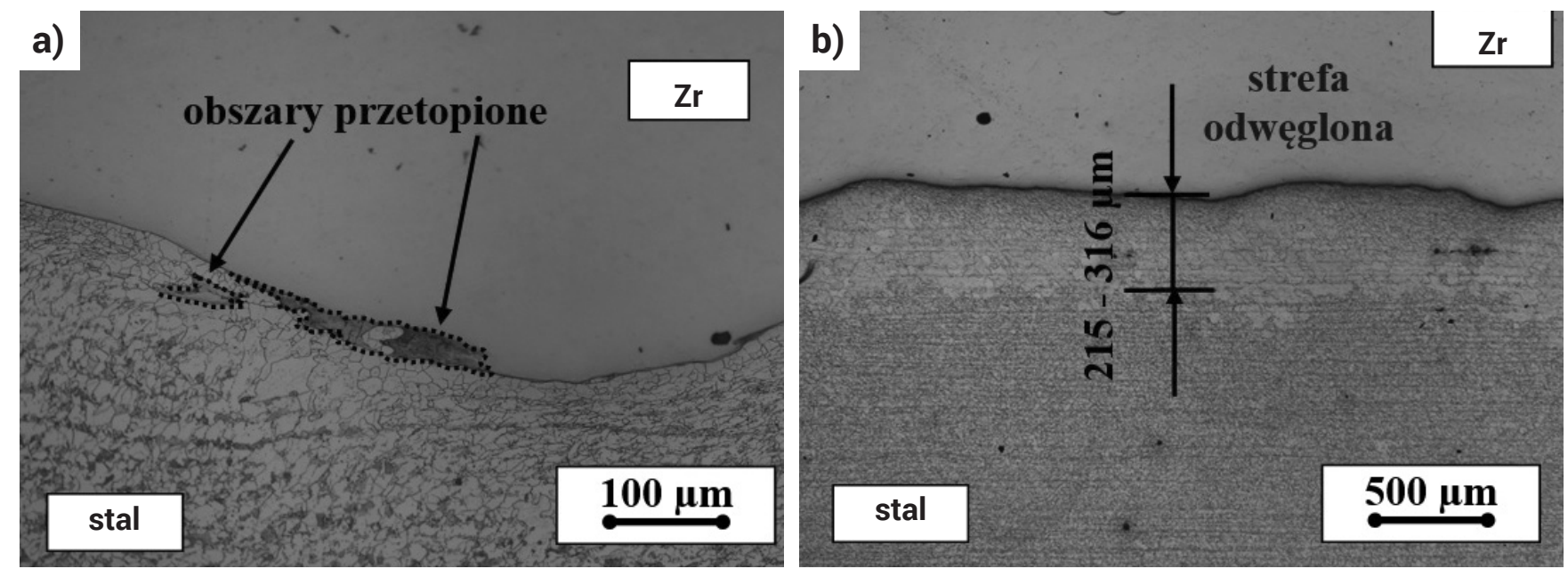

Rys. 2. Struktura w strefie połączenia po wygrzewaniu w temperaturze $600{ }^{\circ} \mathrm{C}$ : a) pr. $\left.10 \mathrm{~h}, \mathrm{~b}\right) \mathrm{pr} .100 \mathrm{~h}$ Fig. 2. Structure in the joint zone after heating at $600^{\circ} \mathrm{C}$ for. a) sp. $\left.10 \mathrm{~h}, \mathrm{~b}\right) \mathrm{sp} .100 \mathrm{~h}$
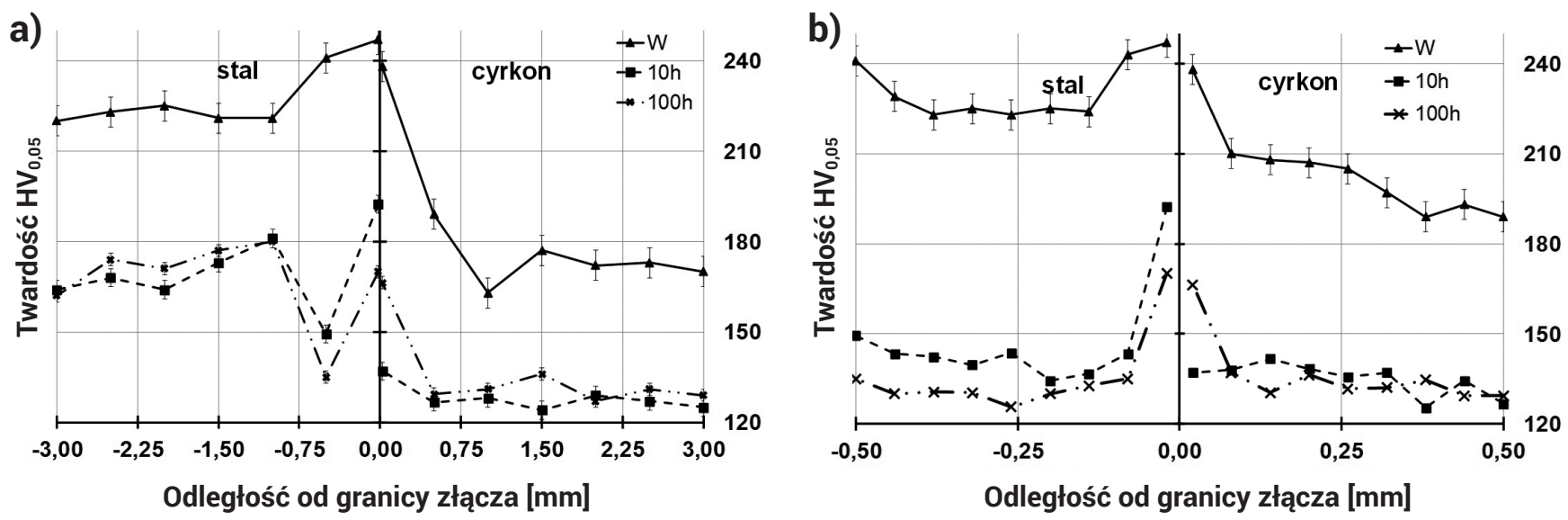

Rys. 3. 'Linie skanowania' pokazujące zmiany średnich wartości twardości dla próbek w stanie po spojeniu i po obróbkach cieplnych w odległości do: a) $3 \mathrm{~mm}$, b) 0,5 mm od granicy połączenia

Fig. 3. 'Line scans' showing the distribution of average hardness values in clad after joining as well as after heat treatment in the distances from the interface up to: a) $3 \mathrm{~mm}$, b) $0.5 \mathrm{~mm}$

odległości od granicy połączenia, twardość systematycznie maleje i w odległości ok. $1 \mathrm{~mm}$ umocnienie stali stabilizuje się. Największe umocnienie występuje w odległości do $0,5 \mathrm{~mm}$ od granicy połączenia (rys. 3b). Analiza zmiany umocnienia w materiale nakładanym (cyrkon) wykazała, że $w$ tym przypadku czas wygrzewania wpływa na zmiany twardości w strefie połączenia. W pierwszym punkcie pomiarowym, dla którego twardość w stanie po spojeniu jest największa, zaobserwowano spadek twardości w cyrkonie o $30 \div 40 \%$ dla obu czasów wygrzewania. Podobny spadek umocnienia w cyrkonie zaobserwowano w odległości $0,5 \mathrm{~mm}$ od złącza. Twardości blachy cyrkonowej w stanie dostawy wynosiła 175 HV. Podobne zmiany obserwowano w materiale podstawowym, w którym wraz ze wzrostem czasu wygrzewania zmniejszało się umocnienie. W przypadku pr. $10 \mathrm{~h}$ obserwowano spadek twardości o $25 \%$, a pr. 100 h do $30 \%$ w stosunku do twardości $w$ tym punkcie $w$ materiale po spojeniu. W odległości $0,5 \mathrm{~mm}$ od granicy połączenia wygrzewanie próbek przez 10 godzin spowodowało spadek twardości o $40 \%$, a przez 100 godzin o $45 \%$ w stosunku do twardości po spojeniu. Dodatkowo przeprowadzono pomiary twardości w wybranych punktach obszarów przetopionych w stanie po spojeniu oraz po obróbce cieplnej (rys. 4), które wykazały, że twardość w strefie przetopionej zmienia się w szerokim zakresie. W przypadku braku obróbki cieplnej minimalna twardość wyniosła $477 \mathrm{HV}$, a maksymalna $896 \mathrm{HV}$ i była prawie 4-krotnie większa od najbardziej umocnionych obszarów w materiałach łączonych (247 HV dla stali).
Przeprowadzona obróbka cieplna przy czasie wygrzewania $10 \mathrm{~h}$ nie spowodowała znacznych zmian twardości w strefie przetopionej, w stosunku do stanu po spojeniu. Twardość dla próbki $10 \mathrm{~h}$ wahała się $\mathrm{w}$ granicach $354 \div 1053 \mathrm{HV}$.

Długi czas wygrzewania $(100 \mathrm{~h})$ spowodował ponad 1,5-krotny wzrost maksymalnych wartości mikrotwardości w obszarach przetopionych, która dla punktu 14 wyniosła 2435 HV (rys. 4b).

\section{Własności wytrzymałościowe}

Przeprowadzone badania wytrzymałości na rozciąganie $\left(R_{m}\right)$ bimetalu w stanie po spojeniu oraz po obróbce cieplnej, pozwoliły na ocenę zmian własności mechanicznych (rys. 5).

Z przeprowadzonych badań wynika, że czas wygrzewania ma znaczący wpływ na wartość wytrzymałości na rozciąganie $\left(R_{m}\right)$ analizowanego układu bimetalowego. Średnia wytrzymałość $R_{m}$ bimetalu po procesie spajania (pr. W) wyniosła $537 \mathrm{MPa}$. Wartość ta świadczy o wysokich właściwości mechanicznych połączenia, zbliżonych do własności stali przed procesem spajania (tabl. I). Wygrzewanie bimetalu w temperaturze $600{ }^{\circ} \mathrm{C}$ przez czas 10 godzin spowodowało ok. $50 \%$ spadek wytrzymałości $R_{m}=284 \mathrm{MPa}$ (rys. 5), co wynika ze spadku twardości w strefie umocnienia, a także zmian strukturalnych spowodowanych rekrystalizacją odkształconych i rozdrobnionych ziaren w pobliżu granicy połączenia. W przypadku pr. $100 \mathrm{~h}$ zaobserwowano ok. 70\% spadek wytrzymałości w stosunku do wytrzymałości po procesie spajania. 


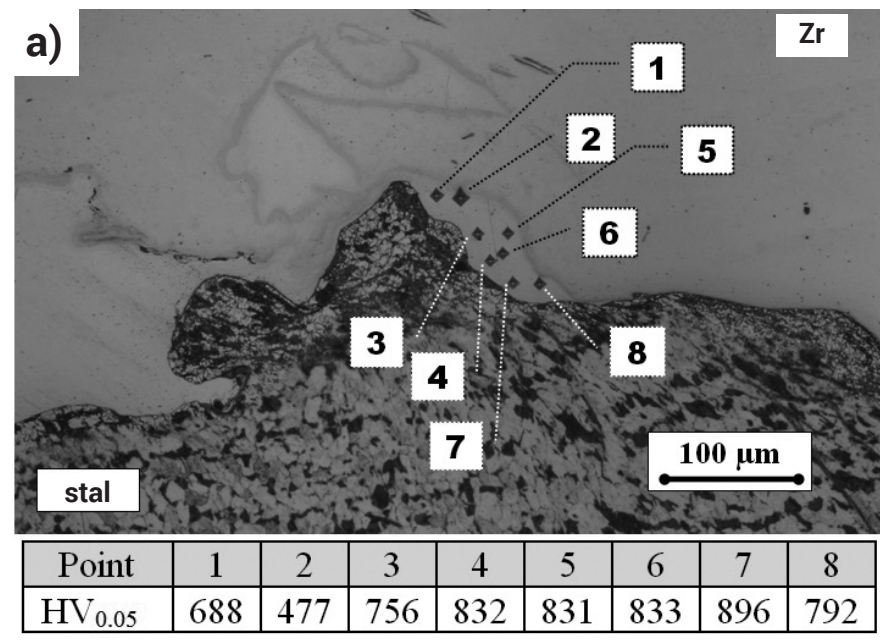

Rys. 4. Mikrotwardość $w$ strefie przetopienia bimetalu cyrkon-stal: a) w stanie po spojeniu, b) po wygrzewaniu w temp. $600{ }^{\circ} \mathrm{C}$ przez 100 godzin

Fig. 4. Microhardness in the zirconium-steel bimetal melting zone: a) after cladding, b) after annealing at the temperature of $600^{\circ} \mathrm{C}$ for 100 hours

Tak niskie właściwości wytrzymałościowe są związane ze znacznym rozrostem ziarna $\mathrm{w}$ strefie połączenia oraz prawie całkowitym odwęgleniem tej strefy po stronie materiału podstawowego (rys. 2b).

\section{Badania zmęczeniowe}

Próbki badano przy amplitudzie obciążenia $\mathrm{M}_{\mathrm{a}}=14,2 \mathrm{~N} \cdot \mathrm{m}$, a zniszczenie nastąpiło $\mathrm{w}$ próbce pr. $10 \mathrm{~h}$, po osiągnięciu trwałości $\mathrm{N}_{\mathrm{f}}=272500$ cykli, natomiast w pr. $100 \mathrm{~h}$, po $\mathrm{N}_{\mathrm{f}}=184000$ cykli. Rozwój pęknięć występował na płaszczyznach prostopadłych do największych naprężeń normalnych i po granicy połączenia obu materiałów. Próbki po obróbce cieplnej miały trwałości mniejsze niż próbka po spojeniu (pr. W). W obu przypadkach inicjacja i propagacja pęknięć następowała od strony stali. Na rysunku 6 pokazano ścieżkę pękania w złączu cyrkon-stal po wygrzewaniu przez 10 godzin, podobny przebieg zaobserwowano w pr. $100 \mathrm{~h}$.

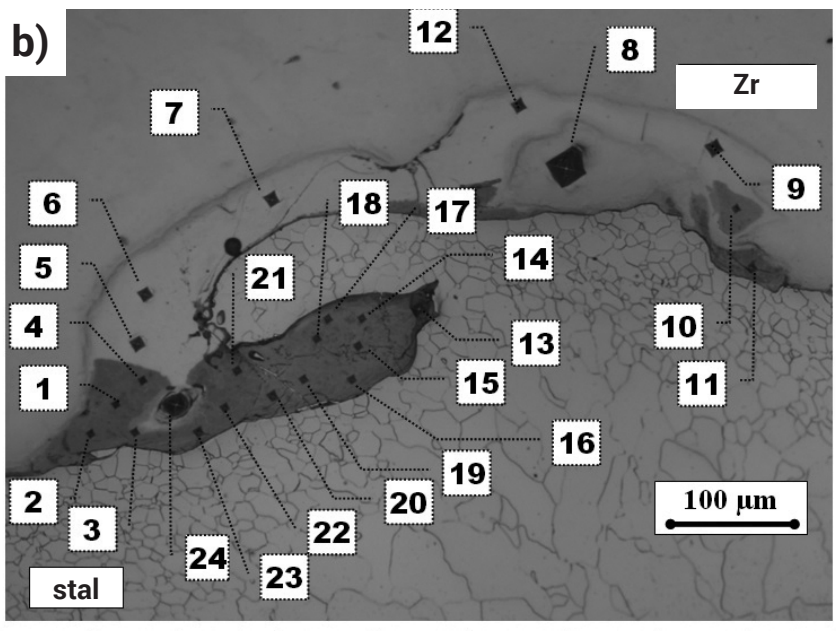

\begin{tabular}{|c|c|c|c|c|c|c|c|c|}
\hline Point & 1 & 2 & 3 & 4 & 5 & 6 & 7 & 8 \\
\hline $\mathrm{HV}_{0.1}$ & 2051 & 2363 & 1941 & 1995 & 936 & 952 & 855 & 157 \\
\hline Point & 9 & 10 & 11 & 12 & 13 & 14 & 15 & 16 \\
\hline $\mathrm{HV}_{0.1}$ & 855 & 2429 & 1941 & 1093 & 1348 & 2435 & 2110 & 2232 \\
\hline Point & 17 & 18 & 19 & 20 & 21 & 22 & 23 & 24 \\
\hline $\mathrm{HV}_{0.1}$ & 2163 & 2296 & 2369 & 1626 & 2049 & 2230 & 1995 & 391 \\
\hline
\end{tabular}

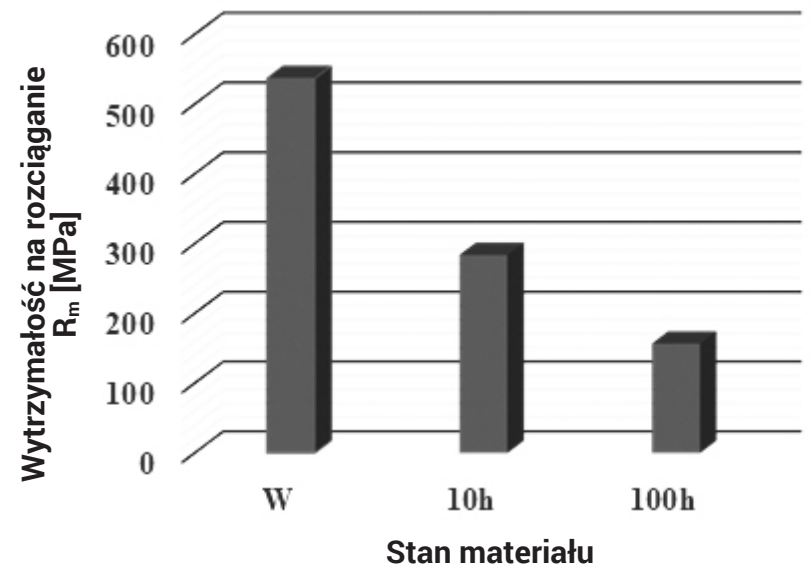

Rys. 5. Wpływ czasu wygrzewania na wytrzymałość na rozciąganie bimetalu Zr-stal

Fig. 5. Influence of the annealing time on the tensile strength of $\mathrm{Zr}$ steel bimetal
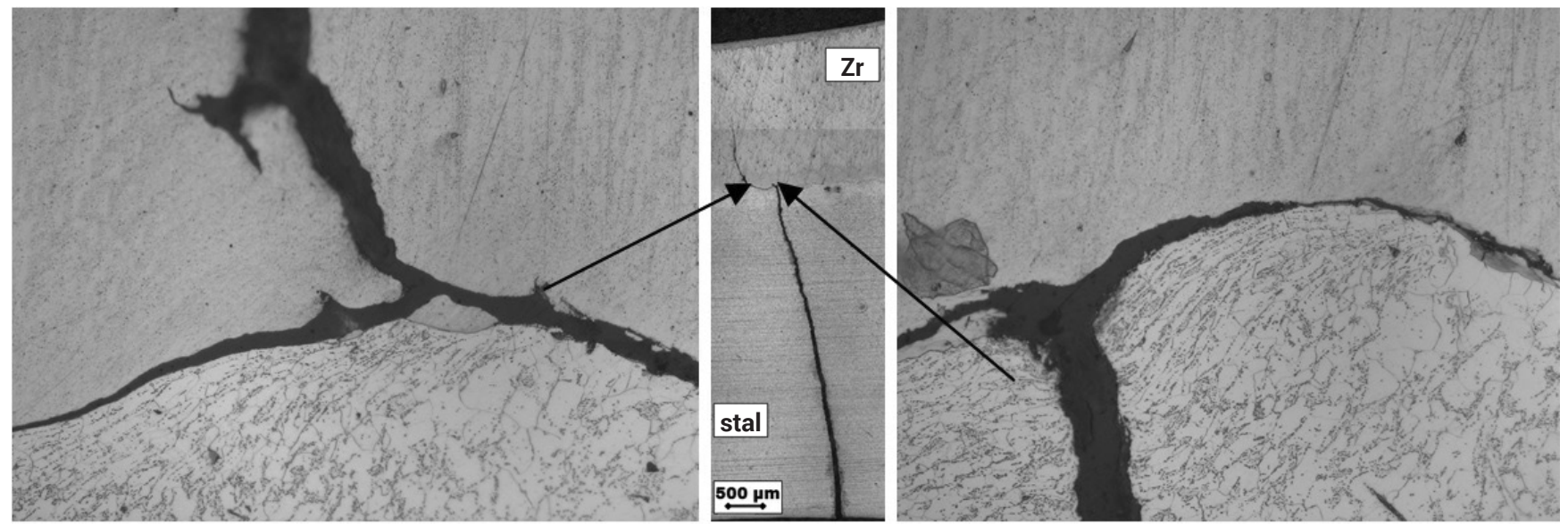

Rys. 6. Mikrostruktura i ścieżka pękania w złączu cyrkon-stal po 10 godzin

Fig. 6. Microstructure and crack path in zirconium-steel joint after 10 hours 


\section{Wnioski}

Przeprowadzone badania oraz analiza otrzymanych wyników pozwala na sformułowanie następujących wniosków:

1. Wzrost czasu wygrzewania prowadzi do zmian strukturalnych w strefie połączenia. Wygrzewanie bimetalu przez 10 godzin wpływa korzystnie, powodując rekrystalizację oraz rozdrobnienie ziarna odkształconego plastycznie podczas procesu zgrzewania. W przypadku długiego czasu wygrzewania (100 godz.) następuje znaczny rozrost ziarna oraz odwęglenie stali w strefie przy granicy połączenia.

2. Występujące w procesie zgrzewania wybuchowego zderzenia płyt z dużą prędkością oraz wysokie ciśnienie w punkcie kontaktu, powodują wzrost twardości, a tym samym znaczne umocnienie w strefie połączenia. Przeprowadzenie obróbki cieplnej w znacznym stopniu zmniejsza umocnienie w strefie połączenia bimetalu, przy czym największe zmiany zaobserwowano w materiale podstawowym.

3. Występujące w strefie złącza warstwy przetopione mają twardość kilkakrotnie większą niż najsilniej umocnione miejsca w materiałach łączonych. Długotrwałe wygrzewanie w wysokiej temperaturze powoduje ponad 1,5-krotny wzrost twardości w analizowanych punktach obszaru przetopionego (rys. 4).

4. Zmiany strukturalne zachodzące podczas obróbki cieplnej wpływają na właściwości mechaniczne badanego bimetalu. Wydłużenie czasu wygrzewania powoduje systematyczny spadek wytrzymałości na rozciąganie i trwałości zmęczeniowej w stosunku do stanu po spojeniu.

\section{Literatura}

[1] Walczak W.: Zgrzewanie wybuchowe metali i jego zastosowanie, WNT, Warszawa 1989

[2] Prażmowski M.: Mechanical properties of zirconium/steel bimetal fabricated by means of explosive welding at varied detonation velocities, Archives of Metallurgy and Materials, vol. 59, pp.1137-1142, 2014.

[3] Prażmowski M., Paul H.: The effect of stand-off distance on the structure and properties of zirconium-carbon steel bimetal produced by explosion welding, Archives of Metallurgy and Materials, vol. 57, pp. 1201-1210, 2012

[4] Paul H., Faryna M., Prażmowski M., Bański R.: Changes In the bonding zone of explosively welded sheets. Archives of Metallurgy and Materials, vol. 56, pp. 1201-1210, 2011

[5] Prażmowski M., Rozumek D., Paul H.: Static and fatigue tests of bimetal Zr-steel made by explosive welding, Engineering Failure Analysis vol. 75, pp. 71-81, 2017.
[6] Prażmowski M., Paul H., Żok F.: The effect of heat treatment on the properties of zirconium-carbon steel bimetal produced by explosion welding, Archives of Metallurgy and Materials, vol. 59, pp.1143-1149, 2014.

[7] Bański R., Paul H., Prażmowski M., Miszczyk M.: Wpływ obróbki cieplnej na zmiany strukturalne oraz własności mechaniczne bimetali Ti/Ni wytwarzanych metodą spajania wybuchowego, Rudy i metale nieżelazne, R 57, nr 5, s. 312-318, 2012.

[8] Prażmowski M., Paul H.: Charakterystyka bimetali cyrkon-stal wykonanych technologią zgrzewania wybuchowego przy zastosowaniu zróżnicowanych parametrów procesu, Przegląd Spawalnictwa, vol. 4, s. 15-21, 2012. 